\title{
Pulse deficit in atrial fibrillation - a different perspective on rhythm or rate control strategy
}

\author{
Serhat Karadavut ${ }^{1}$, Ismail Altintop ${ }^{2}$ \\ 'Department of Cardiology, Kayseri Government Hospital, Kayseri, Turkey \\ ${ }^{2}$ Department of Emergency Medicine, University of Health Science, Kayseri City Hospital, Kayseri, Turkey
}

\author{
Correspondence to: \\ Serhat Karadavut, MD, PhD, \\ Department of Cardiology, \\ Kayseri Government Hospital, \\ 38010 Kayseri, Turkey, \\ phone: +9053339955 78, \\ e-mail: krdvt@yahoo.com \\ Copyright by the Author(s), 2021 \\ Kardiol Pol. 2021; \\ 79 (11): 1231-1238; \\ DOI: $10.33963 /$ KP.a2021.0107 \\ Received: \\ February 22, 2021 \\ Revision accepted: \\ September 9, 2021 \\ Published online: \\ September 9, 2021
}

\begin{abstract}
A B S TR A C T
Background: Pulse deficit (PD) is a frequently unused but crucial clinical finding in atrial fibrillation (AF) diagnosis.
\end{abstract}

Aims: We aimed to investigate the relationship between PD and exercise intolerance in AF patients to remodel the treatment in case of a favorable outcome.

Methods: This prospective study was conducted with 273 permanent AF patients between September 2019 and October 2020. An exercise stress test stratified by age and sex-matched was performed to determine exercise intolerance, and the patients were divided into 2 groups based on physical capacity: low ( $<75$ percentile as Group 1$)(n=160 ; 58.6 \%)$ and adequate ( $\geq 75$ percentile as Group 2) ( $\mathrm{n}=113 ; 41.4 \%)$.

Results: The mean (standard deviation [SD]) PD of exercise intolerance patients was significantly higher than patients with adequate exercise capacity (17 [4] vs. 12 [2]; $P<0.001$ ). Moreover, PD was independently associated with exercise intolerance after adjusting for potential covariates (odds ratio [OR], 0.59; 95\% confidence interval [CI], 0.51-0.69; $P<0.001$ ). In both univariate and multivariable analyses, higher heart rates had a stronger relationship with exercise intolerance (mean [SD], 107 [1 1] vs. 99 [10]; $P<0.001 ; \mathrm{OR}, 0.92 ; 95 \% \mathrm{Cl}, 0.89-0.96 ; P<0.001)$. Also, there was a positive correlation between heart rate and PD $(r=0.431 ; P<0.001)$.

Conclusions: Increased PD was associated with decreased exercise capacity in persistent AF patients. Rhythm control strategy should be considered to increase left ventricular filling pressures in AF patients with high PD and exercise intolerance.

Key words: atrial fibrillation, exercise test, pulse rate

Kardiol Pol 2021; 79, 11: 1231-1238

\section{INTRODUCTION}

Atrial fibrillation (AF) is a leading cause of morbidity and mortality, affecting $1 \%-2 \%$ of the population $[1,2]$. Most patients with AF have palpitations, shortness of breath, weakness, and fatigue, which reduce exercise capacity and impair the quality of life [3]. Symptoms are primarily caused by a loss of atrioventricular synchronization due to rapid and irregular heart rate (HR) [4]. Also, the development of cardiomyopathy due to uncontrolled HR causes exercise intolerance symptoms [5]. Treatments to prevent these symptoms and complications are long-term and costly [6].
Pulse deficit (PD) is a pulse sign that can be effortlessly and non-invasively detected in physical examination in patients with $\mathrm{AF}$. It is the difference between the apical $H R$ and distal HR measurements. In addition to AF, $\mathrm{PD}$ can be examined in premature ventricular contractions, pacemaker patients, severe hypotension, and hypovolemia [7]. While $60-80 \mathrm{~mm} \mathrm{Hg}$ pressure is required to open the aortic valve, $8-14 \mathrm{~mm} \mathrm{Hg}$ pressure is sufficient for the mitral valve to close [8]. The aortic valve cannot be opened due to insufficient left ventricular filling pressure, but PD occurs as a result of mitral valve closure [8]. As a re- 


\section{WHAT'S NEW?}

Rate or rhythm control in permanent atrial fibrillation (AF) management is still a matter of debate today. Current AF guidelines emphasized that advanced evaluation of the pathophysiological process involving clinical characteristics, blood biomarkers, and substrate determination may improve personalized therapy. However, there remains a need for a robust assessment of these processes. The authors revealed that a higher pulse deficit, a noninvasive and simple sign of inadequate left ventricular filling pressure, is associated with lower exercise capacity in AF patients. A significant regression or disappearance of the pulse deficit is physiologically expected with rhythm control. Therefore, a rhythm control strategy will be more beneficial than the rate control in symptomatic AF patients with a more extensive apex-pulse deficit to improve exercise intolerance. The present study reports that pulse deficit counts may be included in the preceding clinical characteristics after their relevance is corroborated by more extensive studies.

sult of inadequate left ventricular filling pressure (LVFP) in patients with $A F$, symptoms such as a decrease in exercise capacity, weakness, fatigue, and an increase in PD in the physical examination will be expected.

Consequently, this suggests that rhythm control will be more effective in relieving symptoms than rate control in patients with AF with high PD. However, there is no data in the literature on this subject. Therefore, this study examines the relationship between PD and exercise capacity in patients with AF and reshapes the treatment accordingly if there is a significant relationship.

\section{METHODS}

\section{Study population and design}

A total of 368 patients diagnosed with permanent AF were included in this prospective study between September 2019 and October 2020. The exclusion criteria were as follows: moderate and severe chronic obstructive pulmonary disease (forced expiratory volume in one second $<80 \%$ ), congestive heart failure (left ventricular ejection fraction [LVEF] $<50 \%$ ), left radial artery obstruction (>50\%), anemia (hemoglobin $<10 \mathrm{~g} / \mathrm{dl}$ ), unable to exercise stress test (orthopedic problems, fragility), elderly ( $>75$ years), obesity (body mass index $>29 \mathrm{~kg} / \mathrm{m}^{2}$ ), severe valvular heart disease. The study was conducted with 273 patients (Figure 1). For PD examinations, one physician counted the left radial pulse with the bare hand simultaneously with another, who counted the apical heartbeat with apical auscultation for one minute in the supine position. Succeeding, the physicians changed places, and the measurements were repeated. The present study was approved by the Local Ethics Committee, and written informed consent was obtained from all participants.

\section{Exercise stress test}

Exercise capacity was evaluated with an exercise stress test performed on a treadmill. The standard Bruce protocol was used. This protocol consists of 10 phases of 3 minutes that enable steady-state development before the workload is increased [9]. Exercise capacities were evaluated by staging formed as a result of metabolic equivalence (MET) values during the exercise test. MET is defined as the workload that occurs during exercise. It refers to the units of oxygen $\left(\mathrm{O}_{2}\right)$ consumed by a person at rest. One metabolic unit refers to $3.5 \mathrm{ml}$ of $\mathrm{O}_{2}$ consumed per minute per kilogram of body weight. MET is calculated using the formula "respiratory $\mathrm{O}_{2}$ uptake/3.5" [9]. Then, estimated MET values were calculated according to age and gender. Veterans Affairs cohort formula for males (estimated METs = $18.7-[0.15 \times$ age $]$ ) and St. James Take Heart Project formula for females (14.7 - $[0.13 \times$ age]) were applied $[10,11]$. Subsequently, percentages of estimated METs were calculated ([achieved METs/estimated METs] $\times 100$ ). According to percentages of estimated METs, the patients were classified into low (Group 1, $<75$ percentile) and adequate (Group 2, $\geq 75$ percentile) physical capacity groups. The test was terminated if significant chest pain, ST depression, or malignant arrhythmia were observed in the patients.

\section{Echocardiographic evaluation}

According to the recommendations of the American Society of Echocardiography, all echocardiographic examinations were performed using a high-quality ultrasound machine (Philips HD 11 XE, Bothell, WA, USA). The left ventricle and atrial diameters were measured using parasternal standard views. Early diastolic mitral inflow velocity (E) was measured using the pulsed wave Doppler method by placing the sample volume at the mitral valve leaflet tips level. Early diastolic mitral annular velocity (e') was measured using pulsed tissue Doppler imaging from the lateral corner of the mitral annulus in the apical 4-chamber view. Five consecutive measurements of $E$ and e' were averaged. E/e' ratio was calculated. LVEF (by Simpson's method) was assessed from the apical 4-chamber view.

\section{Statistical analysis}

Data were presented as mean (standard deviation [SD]) for continuous variables with normal distribution, median (interquartile range [IQR]) for non-normal distribution, and percentage (\%) for categorical variables. The Shapiro-Wilk test assessed the normal distribution of variables. Comparisons of the variables across the groups were performed using a Student t-test or Mann-Whitney U test or a one-way 


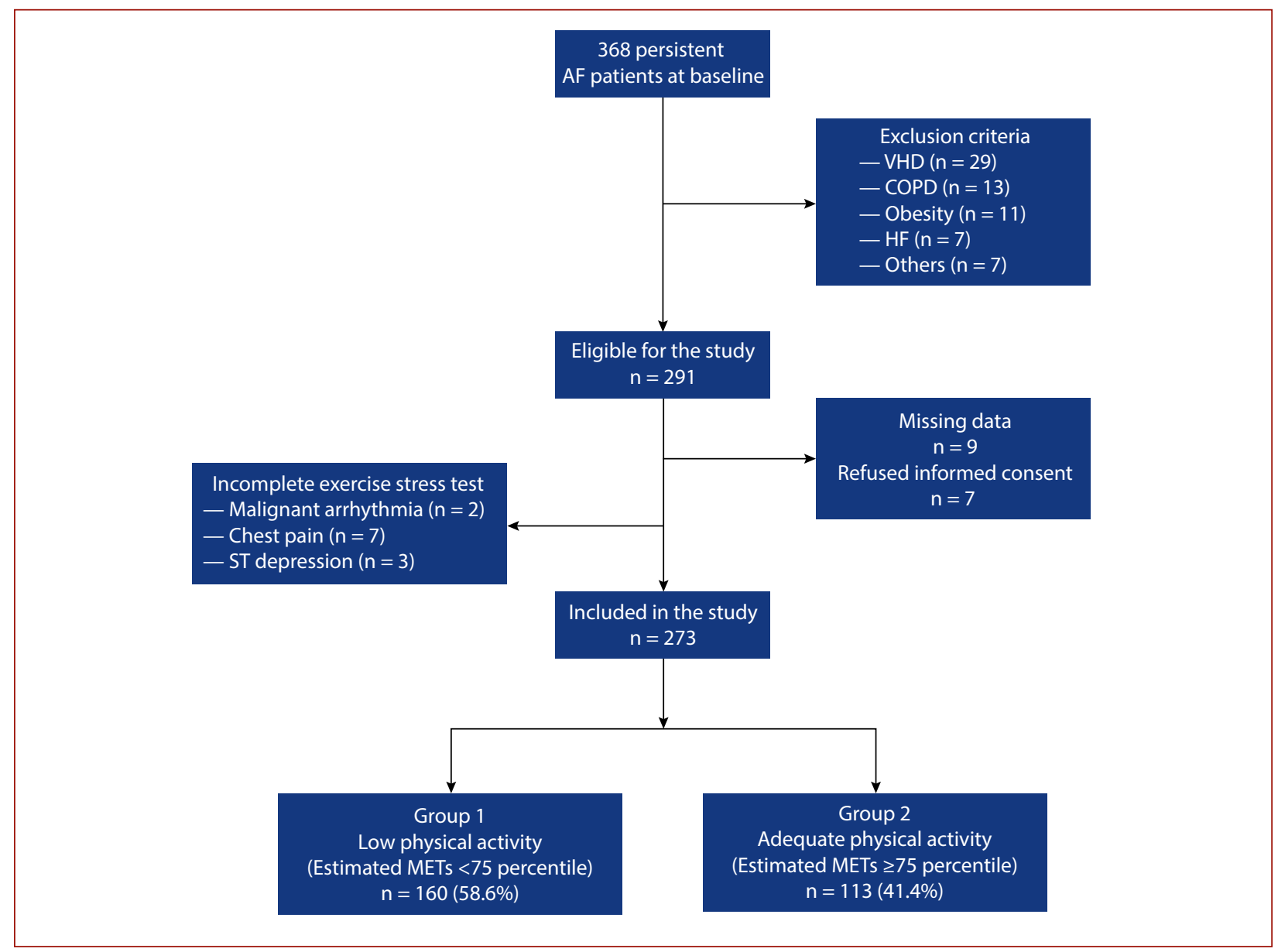

Figure 1. Patient enrollment. A total of 273 permanent AF patients were included in the study. The patients were divided into two groups according to exercise capacity matched by age and sex: Group 1; low physical capacity group (percentage of estimated METs $<75$ percentile) and Group 2; high physical capacity group ( $\geq 75$ percentile)

Abbreviations: AF, atrial fibrillation; $C O P D$, chronic obstructive pulmonary disease; $\mathrm{HF}$, heart failure; METs, metabolic equivalents; VHD, valvular heart disease

ANOVA combined with a Tukey-Kramer post hoc analysis for continuous variables, and Chi-square $\left(x^{2}\right)$ test for categorical variables. Also, logistic regression analyses were performed to define independent predictors of exercise intolerance. Finally, Pearson correlation was applied to determine the correlations. All statistical analyses were studied using the SPSS version 22.0 software package (IBM SPSS, Chicago, IL, USA) and MedCalc version 15.8 statistical software (MedCalc Software, Ostend, Belgium). Statistical significance was defined as $P<0.05$.

\section{RESULTS}

Baseline characteristics of the patients are presented in Table 1. The mean (SD) age of the participants was 60.3 (5.0) years, and the majority were women $(n=165 ; 60.4 \%)$. Based on their exercise capacity, the patients were divided into the Group 1 ( $n=160 ; 58.6 \%)$ and Group $2(n=113 ; 41.4 \%)$. The mean (SD) age of Group 2 was 59.8 (4.6) years, and the mean (SD) age of Group 1 was $61.0(5.4)$ years $(P=0.03)$. The proportion of male participants was significantly higher in Group $1(P<0.001)$. Hypertension and coronary artery disease rate were higher in Group 1 than Group $2(P=0.03)$. There were no differences between the groups for drug usage rates. $\beta$-blocker equivalent dosages had no difference between the groups $(P=0.69)$.

The echocardiography findings of the groups are given in Table 2. There was no significant difference between the mean (SD) LVEF in the 2 groups (57.7 [4.7] vs. 58.2 [4.6]\%; $P=0.46$, respectively). The mean (SD) right ventricle (RV) in Group 1 diameters were slightly wider than Group 2 (35.1 [2.4] and 34.4 [2.3] mm, respectively, $\mathrm{P}=0.03$ ). The mean (SD) E/e' ratio in Group 1 was higher than in Group 2 (9.08 [1.51] vs. 8.71 [1.41]; $P=0.03$, respectively).

The apical heartbeats, distal beats measured from the left radial artery, PD levels, and METs are presented in Table 2. The mean (SD) percentages of the estimated METs of Group 1 and Group 2 were 74.9 (16.8) and 132.0 (22.1) $(P<0.001)$. The mean (SD) PD counts (17 [4] vs. 12 [2] bpm; $P<0.001$, respectively) (Figure 2A), apical HRs (107 [11] vs. 99 [10] bpm; $P<0.001$, respectively) (Figure 2B), and distal HRs (91 [10] vs. 86 [9] bpm; $P=0.001$, respectively) were significantly higher in Group 1 compared to Group 2. When 
Table 1. Clinical characteristics of the study population

\begin{tabular}{|c|c|c|c|c|}
\hline & $\begin{array}{c}\text { Total } \\
n=273\end{array}$ & $\begin{array}{c}\text { Group } 1 \\
\text { n (\%) }=160(58.6)\end{array}$ & $\begin{array}{c}\text { Group } 2 \\
n(\%)=113(41.4)\end{array}$ & P-value \\
\hline Age, years & $60.3(5.0)$ & $61.0(5.4)$ & $59.8(4.6)$ & 0.03 \\
\hline Male, n (\%) & $108(39)$ & $81(50)$ & $27(24)$ & $<0.001$ \\
\hline $\mathrm{BMI}, \mathrm{kg} / \mathrm{m}^{2}$ & $26.2(1.9)$ & $26.2(2.1)$ & $26.1(1.6)$ & 0.91 \\
\hline \multicolumn{5}{|l|}{ History of, n (\%) } \\
\hline CAD & $53(19)$ & $38(23)$ & $15(13)$ & 0.03 \\
\hline Stroke/TIA & $35(12)$ & $20(14)$ & $15(10)$ & 0.48 \\
\hline Hypertension & $226(82)$ & $139(86)$ & $87(77)$ & 0.03 \\
\hline Diabetes mellitus & $59(21)$ & $37(23)$ & $22(19)$ & 0.47 \\
\hline Active smoking & $71(26)$ & $37(23)$ & $34(30)$ & 0.19 \\
\hline \multicolumn{5}{|l|}{ Laboratory data } \\
\hline Hemoglobin, g/dl & $13.6(1.6)$ & $13.6(1.6)$ & $13.5(1.5)$ & 0.63 \\
\hline WBC, $10^{3} / \mu \mathrm{l}$ & $7.6(2.1)$ & $7.8(2.4)$ & $7.4(1.6)$ & 0.12 \\
\hline Creatinine, mg/dl & $0.8(0.2)$ & $0.8(0.2)$ & $0.7(0.1)$ & 0.12 \\
\hline Glucose, mg/dl & $99(61-356)$ & $101(61-313)$ & $97(61-356)$ & 0.10 \\
\hline \multicolumn{5}{|l|}{ Medications, n (\%) } \\
\hline ACEi/ARB & $165(60)$ & $103(64)$ & $62(55)$ & 0.11 \\
\hline BB & $188(68)$ & $113(70)$ & $75(66)$ & 0.45 \\
\hline Digoxin & $128(46)$ & $68(48)$ & $60(44)$ & 0.51 \\
\hline $\mathrm{CCB}$ & $66(24)$ & $41(25)$ & $25(22)$ & 0.50 \\
\hline BB doses, mg/day & $50(25-200)$ & $50(25-200)$ & $50(25-200)$ & 0.69 \\
\hline
\end{tabular}

Group 1: low physical capacity ( $<75$ percentile), Group 2: adequate physical capacity ( $\geq 75$ percentile). BB doses were presented as metoprolol equivalent doses as follows: metoprolol $50 \mathrm{mg}=$ bisoprolol $5 \mathrm{mg}=$ carvedilol $12.5 \mathrm{mg}=$ nebivolol $5 \mathrm{mg}$ [32] placing them in a unique position to prescribe the antihypertensive agent best suited to the individual patient. In individuals with diabetes mellitus, blood pressure (BP). Values are presented as the mean (SD), median (IQR), or $n(\%)$

Abbreviations: $A C E i$, angiotensin-converting enzyme inhibitor; $A R B$, angiotensin receptor blocker; $B B$, $\beta$-blockers; $B M I$, body mass index; $C A D$, coronary artery disease; $C C B$, non-dihydropyridine calcium channel blocker; TIA, transient ischemic attack; WBC, white blood cell; other — see Figure 1

Table 2. Echocardiographic, exercise treadmill parameters and pulse examination findings

\begin{tabular}{|c|c|c|c|c|}
\hline & $\begin{array}{c}\text { Total } \\
n=273\end{array}$ & $\begin{array}{c}\text { Group } 1 \\
\text { n (\%) }=160(58.6)\end{array}$ & $\begin{array}{c}\text { Group } 2 \\
n(\%)=113(41.4)\end{array}$ & $P$-value \\
\hline \multicolumn{5}{|l|}{ Echocardiography } \\
\hline LVEF, \% & $57.9(4.7)$ & $57.7(4.7)$ & $58.2(4.6)$ & 0.46 \\
\hline LVSD, mm & $33.2(1.7)$ & $33.3(1.7)$ & $33.1(1.8)$ & 0.24 \\
\hline LVDD, mm & $48.0(2.2)$ & $48.1(2.2)$ & $47.8(2.2)$ & 0.31 \\
\hline $\mathrm{RV}, \mathrm{mm}$ & $34.8(2.4)$ & $35.1(2.4)$ & $34.4(2.3)$ & 0.03 \\
\hline $\mathrm{LA}, \mathrm{mm}$ & $33.2(2.5)$ & $33.3(2.5)$ & $33.0(2.4)$ & 0.32 \\
\hline$E / e^{\prime}$ & $8.82(1.49)$ & $9.08(1.51)$ & $8.71(1.41)$ & 0.03 \\
\hline \multicolumn{5}{|l|}{ Pulse examination } \\
\hline Apical HR, bpm & $104(11)$ & $107(11)$ & $99(10)$ & $<0.001$ \\
\hline Distal HR, bpm & $89(10)$ & $91(10)$ & $86(9)$ & 0.001 \\
\hline PD, bpm & $14(4)$ & $17(4)$ & $12(2)$ & $<0.001$ \\
\hline Peak exercise capacity (METs) & $7.63(2.44)$ & $6.21(1.71)$ & $9.64(1.83)$ & $<0.001$ \\
\hline Estimated METs, \% & $98.5(34.1)$ & $74.9(16.8)$ & $132.0(22.1)$ & $<0.001$ \\
\hline
\end{tabular}

Values are presented as the mean (SD)

Abbreviations: $E$, early left ventricular filling velocity; $e^{\prime}$, tissue velocity during early left ventricular filling; $H R$, heart rate; LA, left atrium; LVDD, left ventricular diastolic diameter; LVEF, left ventricular ejection fraction; LVSD, left ventricular systolic diameter; PD, pulse deficit; RV, right ventricle; other — see Figure 1 and Table 1

the patients' estimated METs were classified into quartiles, the mean (SD) PDs were significantly different in all quartiles (18 [4], 15 [3], 13 [3], and 11 [2] bpm, respectively) (Figure 2C). The mean (SD) apical HRs were significantly higher in the third and fourth quartile (102 [11] and 97 [8] bpm, respectively). However, there was no significant difference between the first and second quartiles (108 [10] and 108 [12] bpm, respectively) (Figure 2D).

Logistic regression analyses demonstrated the associations between clinical variables and exercise intolerance (Table 3). After a multivariable adjustment, age, sex, apical $H R$, and PD were independently associated with limited exercise tolerance. Covariates included significant variables in the univariate analysis, LVEF, beta-blocker doses, and the proportion of digoxin and non-dihydropyridine calcium channel blocker usage. In the bivariate correlation analysis, the E/e' ratio, apical $H R$, and left atrial (LA) volume significantly correlated with $P D(r=0.219 ; P<0.001 ; r=0.431$; $P<0.001 ; r=0.224 ; P<0.001$, respectively) (Table 4).

\section{DISCUSSION}

This study demonstrates the clinical importance of PD examination in AF patients. While billions of dollars are spent every year on $A F$, it has been shown that PD examination, 


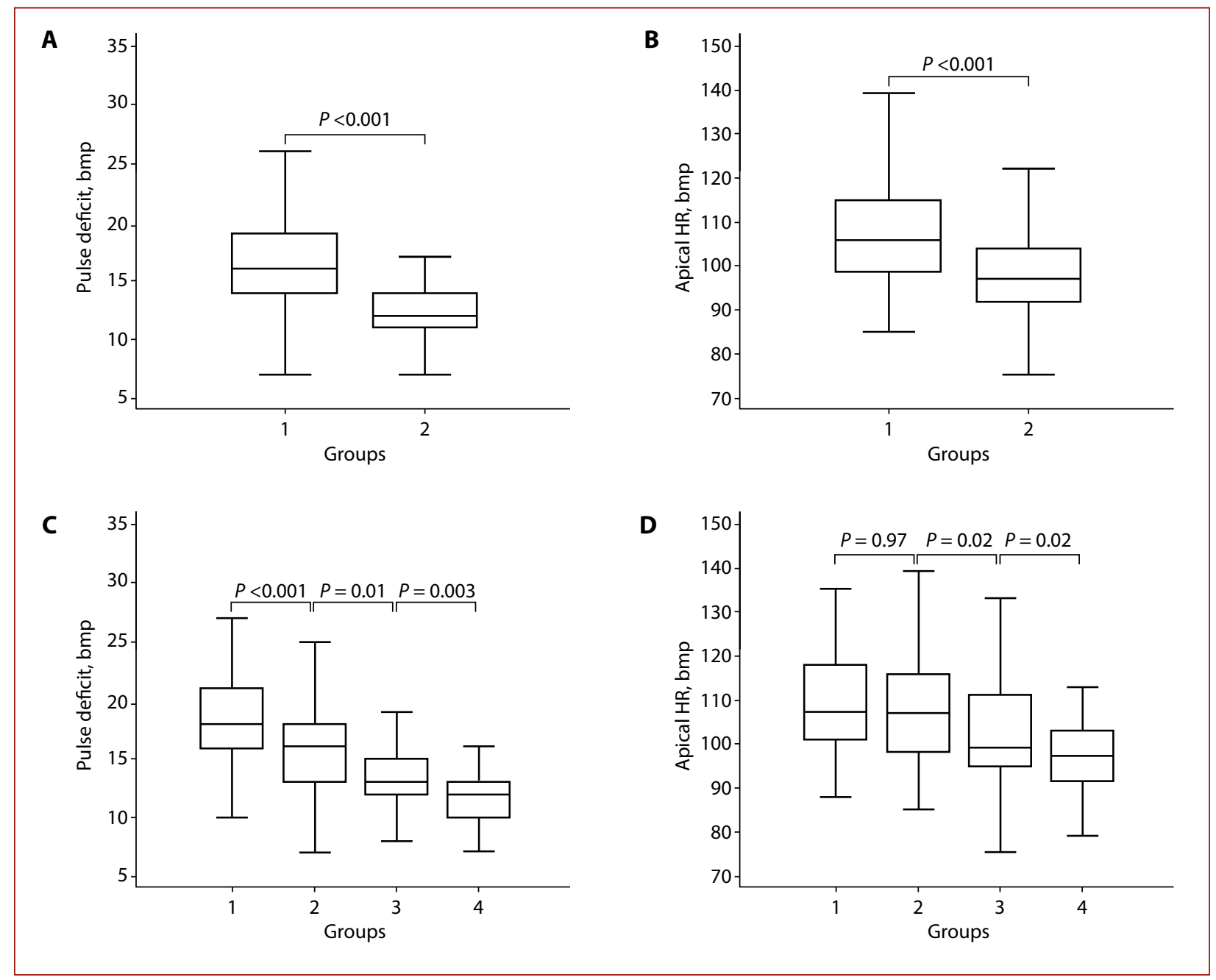

Figure 2. Box plots graphs show the distribution of the PD and apical HR between the groups. The differences between PD counts (A) and apical HR (B) in Group 1 and 2. C. and D. Depict patients' PD and apical HR distributions divided according to quartiles of estimated METs, respectively. First quartile: percentage of estimated METs $<25^{\text {th }}$ percentile $(n=67)$, second: $25-50^{\text {th }}(n=68)$, third: $50-75^{\text {th }}(n=70)$, fourth: $\geq 75^{\text {th }}(\mathrm{n}=68)$

Abbreviations: see Figure 1 and Table 2

Table 3. Univariate and multivariable analysis for exercise intolerance

\begin{tabular}{|c|c|c|c|c|}
\hline \multirow{2}{*}{ Variables } & \multicolumn{2}{|c|}{ Univariate analyses } & \multicolumn{2}{|c|}{ Multivariable adjusted } \\
\hline & OR (95\% CI) & $P$-value & OR $(95 \% \mathrm{Cl})$ & $P$-value \\
\hline Age & $\begin{array}{c}1.06 \\
(1.01-1.12)\end{array}$ & 0.03 & $\begin{array}{c}1.27 \\
(1.15-1.39)\end{array}$ & $<0.001$ \\
\hline Gender & $\begin{array}{c}0.30 \\
(0.18-0.52)\end{array}$ & $<0.001$ & $\begin{array}{c}0.05 \\
(0.01-0.14)\end{array}$ & $<0.001$ \\
\hline Hypertension & $\begin{array}{c}1.97 \\
(1.04-3.73)\end{array}$ & 0.03 & $\begin{array}{c}2.96 \\
(0.99-8.84)\end{array}$ & 0.06 \\
\hline CAD & $\begin{array}{c}2.03 \\
(1.05-3.91)\end{array}$ & 0.03 & $\begin{array}{c}1.24 \\
(0.47-3.28)\end{array}$ & 0.65 \\
\hline PD & $\begin{array}{c}0.68 \\
(0.61-0.75)\end{array}$ & $<0.001$ & $\begin{array}{c}0.59 \\
(0.51-0.69)\end{array}$ & $<0.001$ \\
\hline Apical HR & $\begin{array}{c}0.92 \\
(0.90-0.95)\end{array}$ & $<0.001$ & $\begin{array}{c}0.92 \\
(0.89-0.96)\end{array}$ & $<0.001$ \\
\hline LVEF & $\begin{array}{c}1.01 \\
(0.96-1.07)\end{array}$ & 0.46 & $\begin{array}{c}1.03 \\
(0.95-1.12)\end{array}$ & 0.35 \\
\hline$E / e^{\prime}$ & $\begin{array}{c}0.83 \\
(0.70-0.99)\end{array}$ & 0.03 & $\begin{array}{c}0.86 \\
(0.67-1.11)\end{array}$ & 0.27 \\
\hline RV & $0.89(0.80-0.99)$ & 0.03 & $\begin{array}{c}0.97 \\
(0.83-1.14)\end{array}$ & 0.75 \\
\hline
\end{tabular}

Abbreviations: $\mathrm{Cl}$, confidence interval; OR, odds ratio; other — see Table 1 and Table 2 
Table 4. Correlations between PD and significant variables

\begin{tabular}{lcc}
\multicolumn{1}{c|}{ Variables } & R & P-value \\
\hline Apical HR & 0.431 & $<0.001$ \\
Distal HR & 0.079 & 0.19 \\
LVEF & 0.057 & 0.34 \\
LA & 0.224 & $<0.001$ \\
E/e' & 0.219 & $<0.001$ \\
\hline
\end{tabular}

Abbreviations: see Table 2

an easy, cheap, and noninvasive method, should not be overlooked. Even after adjusting significant covariates, the researchers found that PD was independently associated with exercise capacity. PD was significantly higher in the low exercise capacity group.

Previous studies reported that high PD had a strong relationship with inadequate LVFP resulting decrease in the stroke volume $[8,12]$. Accordingly, PD counts will help determine whether an adequate stroke volume has been achieved quickly and easily after given treatment. Also, an increase in PD was significantly associated with submaximal exercise in healthy volunteers [13]. A declined stroke volume is blamed primarily for symptoms of exercise intolerance such as shortness of breath, weakness, and fatigue in patients with AF [14]. Therefore, the authors recommend $P D$ examination to gain insight into the stroke volume in AF patients with exercise intolerance symptoms in the present study.

Another remarkable outcome of the present study was that higher HR was associated with higher PD and limited exercise capacity. We found a positive relationship between PD and apical HR. This relationship was attributed to the inadequate LVFP caused by the higher HR. However, PD was high in patients with normal HR levels $(<100 \mathrm{bpm})$ and low exercise capacity. The authors considered that R-R intervals' irregularity was the fundamental cause of low filling pressure in average HR conditions. Therefore, this suggests that rhythm control will produce more successful results than rate control in AF patients with more outstanding exercise intolerance complaints. Many studies previously emphasized that rate control strategy should be applied to all patients, and rhythm control treatment should be individualized $[15,16]$. Given the mentioned findings, we consider that PD examination will help individualize rhythm control.

This study also showed that high apical HR was inversely proportional to exercise capacity, independently of PD levels. In limited exercise capacity, a reduced stroke volume due to inadequate left ventricular filling pressure caused by increased HR seems to be the most likely mechanism. On the other hand, increased HRs may also be to compensate for decreased cardiac output. Many studies reported that higher HR was associated with a lower quality of life in AF [17-19]. Kato et al. [20] showed that patients with AF achieved their best exercise capacity when their resting $H R$ was between $80-100 / \mathrm{min}$, and more often, rate control had no effect. Rawles et al. [21] reported that the maintenance of the HR below 90/min in AF patients may have beeficial effects on cardiac output and symptom control. Contrary to the studies mentioned above, there have been no precise data about optimal HR in patients with AF in the guidelines [2]. The guidelines recommend rhythm control in the case of AF patients, who are symptomatic despite rate control and have a poor quality of life [2]. However, as the objective data, PD counts may be more helpful in evaluating rhythm control option in AF patients.

Previous studies showed that increased E/e' ratios in AF patients were associated with diastolic dysfunction and decreased exercise capacity $[22,23]$. Furthermore, Li et al. [24] reported a relationship between increased E/e' and decreased LVFP. Additionally, a relationship between inadequate LVFP and exercise intolerance in patients with AF was shown in a previous study [25]. All these studies show that the loss of atrioventricular synchronization and deterioration in myocardial relaxation are also causative in the formation of insufficient LVFP. In this study, E/e' ratio was associated with exercise intolerance in the univariate analysis; nevertheless, the E/e' was not an independent predictor of exercise intolerance in the multivariable regression analysis. In the correlation analysis, the $\mathrm{E} / \mathrm{e}^{\prime}$ ratios weakly but significantly contributed to PD levels.

Previous studies reported that the New York Heart Association classification, MET values in exercise stress test performed with treadmill, or symptom-limited cardiopulmonary testing with expired gas analysis were used to evaluate exercise intolerance $[26,27]$. Our study measured exercise capacity by the MET values in the exercise stress test performed on the treadmill. This study also evaluated functional capacity more objectively by using METs adjusted for age and sex. In this way, parameters directly related to MET values were also taken into account.

When we classified the patients into quartiles, the PD was significantly higher in each decreasing quarter. Also, apical HR was significantly lower in the upper quartiles. However, apical HR did not differ significantly below the $50^{\text {th }}$ percentile. Despite the deterioration in physical capacity, the increase in heart rate did not differ significantly in the lower quartiles, while PD increased significantly at each stage. This result considered that PD was more specific than heart rate in AF patients with insufficient functional capacity.

Abhayaratna et al. [28] showed that an increased LA size was associated with exercise intolerance. Azarbal et al. [29] reported that exercise capacity in AF patients was independent of LA sizes. In this study, LA dimensions were not associated with lower exercise capacity. However, an increased LA size had a significant relationship with higher PD. Therefore, PD counts may be involved in assessing factors favoring rhythm control in AF patients, such as the LA size. 


\section{Limitations}

First, estimated METs were used to evaluate the exercise capacity of the patients. More objective results could be obtained with symptom-limited cardiopulmonary testing with expired gas analysis. Second, there are no generally accepted age and sex-adjusted MET values for evaluating exercise intolerance. Therefore, the value used was determined, taking into account previous studies [30, 31]. Also, the lack of sufficient data on PD in the literature was another limiting factor.

\section{CONCLUSIONS}

Increased PD is associated with insufficient exercise capacity in persistent AF patients. In AF patients with predominant exercise intolerance symptoms and high PD, rhythm control should primarily be considered if there are no other obstacles to make left ventricular filling sufficient. Long-term studies are needed to evaluate symptoms and exercise capacity of patients whose PD is reduced by providing rhythm control.

\section{Article information}

Conflict of interest: SS is the author of several patents and shareholder of Medicine S.A. No products were used in this case.

Open access: This article is available in open access under Creative Common Attribution-Non-Commercial-No Derivatives 4.0 International (CC BY-NC-ND 4.0) license, allowing to download articles and share them with others as long as they credit the authors and the publisher, but without permission to change them in any way or use them commercially. For commercial use, please contact the journal office at kardiologiapolska@ptkardio.pl.

How to cite: Karadavut S, Altintop I. Pulse deficit in atrial fibrillation - a different perspective on rhythm or rate control strategy. Kardiol Pol. 2021; 79(11): 1231-1238, doi: 10.33963/KP.a2021.0107.

\section{REFERENCES}

1. Chugh SS, Havmoeller R, Narayanan K, et al. Worldwide epidemiology of atrial fibrillation: a Global Burden of Disease 2010 Study. Circulation. 2014; 129(8):837-847, doi: 10.1161/CIRCULATIONAHA.113.005119, indexed in Pubmed: 24345399.

2. Hindricks G, Potpara T, Dagres N, et al. ESC Scientific Document Group. 2020 ESC Guidelines for the diagnosis and management of atrial fibrillation developed in collaboration with the European Association for Cardio-Thoracic Surgery (EACTS): The Task Force for the diagnosis and management of atrial fibrillation of the European Society of Cardiology (ESC) Developed with the special contribution of the European Heart Rhythm Association (EHRA) of the ESC. Eur Heart J. 2021; 42(5): 373-498, doi: 10.1093/eurheartj/ehaa612, indexed in Pubmed: 32860505.

3. Singh SN, Tang XC, Singh BN, et al. SAFE-T Investigators. Quality of life and exercise performance in patients in sinus rhythm versus persistent atrial fibrillation: a Veterans Affairs Cooperative Studies Program Substudy. J Am Coll Cardiol. 2006; 48(4): 721-730, doi: 10.1016/j.jacc.2006.03.051, indexed in Pubmed: 16904540.

4. Savelieva I, Camm AJ. Clinical relevance of silent atrial fibrillation: prevalence, prognosis, quality of life, and management. J Interv Card Electrophysiol. 2000; 4(2): 369-382, doi: 10.1023/a:1009823001707, indexed in Pubmed: 10936003.

5. Goette A, Kalman JM, Aguinaga L, et al. Document Reviewers. EHRA/HRS/APHRS/SOLAECE expert consensus on atrial cardiomyopathies: definition, characterization, and clinical implication. Europace. 2016; 18(10): 1455-1490, doi: 10.1093/europace/euw161, indexed in Pubmed: 27402624.
6. Le Heuzey JY, Paziaud O, Piot O, et al. Cost of care distribution in atrial fibrillation patients: the COCAF study. Am Heart J. 2004; 147(1): 121-126, doi: 10.1016/s0002-8703(03)00524-6, indexed in Pubmed: 14691429.

7. McConnell EA. Assessing pulse deficit. Nursing. 1993; 23(11): 18, doi: 10.1097/00152193-199311000-00009, indexed in Pubmed: 8233155.

8. Mawatari K, Sanada J, Kuroiwa N, et al. Mechanism of production of pulse deficit in atrial fibrillation: assessment by blood flow dynamics [article in Japanese]. J Cardiol. 1988; 18(1): 197-205, indexed in Pubmed: 3221309.

9. Bruce RA, Blackmon JR, Jones JW, et al. Exercising testing in adult normal subjects and cardiac patients. 1963. Ann Noninvasive Electrocardiol. 2004; 9(3): 291-303, doi: 10.1111/j.1542-474X.2004.93003.x, indexed in Pubmed: 15245347.

10. Gulati M, Pandey DK, Arnsdorf MF, et al. Exercise capacity and the risk of death in women: the St James Women Take Heart Project. Circulation. 2003; 108(13): 1554-1559, doi: 10.1161/01.CIR.0000091080.57509.E9, indexed in Pubmed: 12975254.

11. Morris CK, Myers J, Froelicher VF, et al. Nomogram based on metabolic equivalents and age for assessing aerobic exercise capacity in men. J Am Coll Cardiol. 1993; 22(1): 175-182, doi: 10.1016/0735-1097(93)90832-I, indexed in Pubmed: 8509539.

12. Otsuji $Y$, Kisanuki $A$, Toda $H$, et al. Influence of left ventricular filling profile during preceding control beats on the occurrence of pulse deficit caused by ventricular premature contractions. Eur Heart J. 1993; 14(8): 1044-1049, doi: 10.1093/eurheartj/14.8.1044, indexed in Pubmed: 7691601.

13. Roseguini BT, Narro F, Oliveira AR, et al. Estimation of the lactate threshold from heart rate response to submaximal exercise: the pulse deficit. Int J Sports Med. 2007; 28(6): 463-469, doi: 10.1055/s-2006-924584, indexed in Pubmed: 17111313.

14. Saur J, Trinkmann F, Doesch C, et al. Non-invasive measurement of cardiac output during atrial fibrillation: comparison between cardiac magnetic resonance imaging and inert gas rebreathing. Cardiology. 2010; 115(3): 212-216, doi: 10.1159/000288712, indexed in Pubmed: 20197660.

15. Prystowsky E, Padanilam B, Fogel R. Treatment of atrial fibrillation. JAMA. 2015; 314(3): 278-288, doi: 10.1001/jama.2015.7505.

16. Roy D, Talajic M, Nattel S, et al. Atrial Fibrillation and Congestive Heart Failure Investigators. Rhythm control versus rate control for atrial fibrillation and heart failure. N Engl J Med. 2008; 358(25): 2667-2677, doi: 10.1056/NEJMoa0708789, indexed in Pubmed: 18565859.

17. Shantsila A, Gupta D, Lip GYH. Heart rate variability changes following catheter ablation for atrial fibrillation. Kardiol Pol. 2020; 78(3): 179-180, doi: 10.33963/KP.15249, indexed in Pubmed: 32218387.

18. Zyśko $D$, Persson $A$, Obremska $M$, et al. The importance of the longest $\mathrm{R}-\mathrm{R}$ interval on 24-hour electrocardiography for mortality prediction in patients with atrial fibrillation. Kardiol Pol. 2021; 79(3): 311-318, doi: 10.33963/KP.15820, indexed in Pubmed: 33599460.

19. Marinković $M$, Mujović $N$, Vučićević $V$, et al. A square root pattern of changes in heart rate variability during the first year after circumferential pulmonary vein isolation for paroxysmal atrial fibrillation and their relation with longterm arrhythmia recurrence. Kardiol Pol. 2020; 78(3): 209-218, doi: 10.33963/KP.15187, indexed in Pubmed: 32049070.

20. Kato $Y$, Suzuki S, Uejima T, et al. The relationship between resting heart rate and peak VO2: A comparison of atrial fibrillation and sinus rhythm. Eur J Prev Cardiol. 2016; 23(13): 1429-1436, doi: 10.1177/2047487316633885, indexed in Pubmed: 26879567

21. Rawles JM. What is meant by a "controlled" ventricular rate in atrial fibrillation? Br Heart J. 1990; 63(3): 157-161, doi: 10.1136/hrt.63.3.157, indexed in Pubmed: 2183858.

22. Borlaug BA, Nishimura RA, Sorajja P, et al. Exercise hemodynamics enhance diagnosis of early heart failure with preserved ejection fraction. Circ Heart Fail. 2010; 3(5): 588-595, doi: 10.1161/CIRCHEARTFAILURE.109.930701, indexed in Pubmed: 20543134.

23. Kosiuk J, Van Belle Y, Bode K, et al. Left ventricular diastolic dysfunction in atrial fibrillation: predictors and relation with symptom severity. J Cardiovasc Electrophysiol. 2012; 23(10): 1073-1077, doi: 10.1111/j.15408167.2012.02368.x, indexed in Pubmed: 22672521.

24. Li C, Zhang J, Zhou C, et al. Will simultaneous measurement of E/e' index facilitate the non-invasive assessment of left ventricular filling pressure in patients with non-valvular atrial fibrillation? Eur J Echocardiogr. 2010; 
11(3): 296-301, doi: 10.1093/ejechocard/jep218, indexed in Pubmed: 20022868.

25. Chen SM, He R, Li WH, et al. Relationship between exercise induced elevation of left ventricular filling pressure and exercise intolerance in patients with atrial fibrillation. J Geriatr Cardiol. 2016; 13(6):546-551, doi: 10.11909/j.issn.1671-5411.2016.06.016, indexed in Pubmed: 27582773.

26. Lauer M, Froelicher ES, Williams M, et al. American Heart Association Council on Clinical Cardiology, Subcommittee on Exercise, Cardiac Rehabilitation, and Prevention. Exercise testing in asymptomatic adults: a statement for professionals from the American Heart Association Council on Clinical Cardiology, Subcommittee on Exercise, Cardiac Rehabilitation, and Prevention. Circulation. 2005; 112(5): 771-776, doi: 10.1161/CIRCULATIONAHA.105.166543, indexed in Pubmed: 15998671.

27. Kubo $\mathrm{T}$, Kitaoka $\mathrm{H}$, Okawa $\mathrm{M}$, et al. Clinical impact of atrial fibrillation in patients with hypertrophic cardiomyopathy. Results from Kochi RYOMA Study.Circ J.2009; 73(9):1599-1605, doi:10.1253/circj.cj-09-0140, indexed in Pubmed: 19590139.
28. Abhayaratna WP, Seward JB, Appleton CP, et al. Left atrial size: physiologic determinants and clinical applications. J Am Coll Cardiol. 2006; 47(12): 2357-2363, doi: 10.1016/j.jacc.2006.02.048, indexed in Pubmed: 16781359.

29. Azarbal F, Singh M, Finocchiaro G, et al. Exercise capacity and paroxysmal atrial fibrillation in patients with hypertrophic cardiomyopathy. Heart. 2014; 100(8): 624-630, doi: 10.1136/heartjnl-2013-304908, indexed in Pubmed: 24326897.

30. Carrick-Ranson G, Hastings $\mathrm{J}$, Bhella PS, et al. The effect of lifelong exercise dose on cardiovascular function during exercise. J Appl Physiol (1985). 2014; 116(7): 736-745, doi: 10.1152/japplphysiol.00342.2013, indexed in Pubmed: 24458750.

31. Kwon O, Park S, Kim YJ, et al. The exercise heart rate profile in master athletes compared to healthy controls. Clin Physiol Funct Imaging. 2016; 36(4): 286-292, doi: 10.1111/cpf.12226, indexed in Pubmed: 25532888.

32. McGill JB. Optimal use of beta-blockers in high-risk hypertension: a guide to dosing equivalence. Vasc Health Risk Manag. 2010; 6: 363-372, doi: 10.2147/vhrm.s6668, indexed in Pubmed: 20539838. 